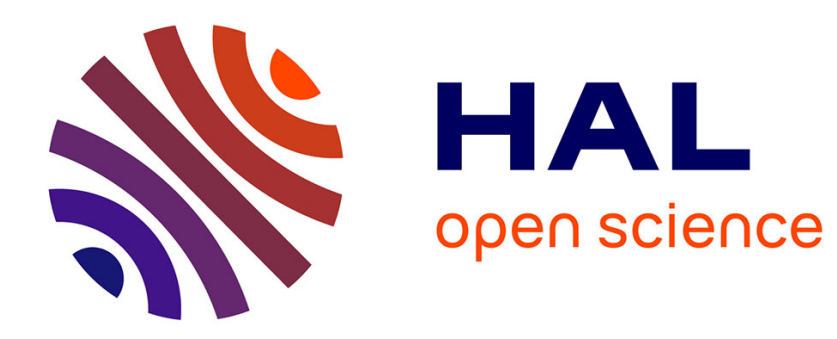

\title{
Magnetic Anisotropy of Ba Ferrite Particles at Low Temperature
}

\author{
G. Bottoni
}

\section{To cite this version:}

G. Bottoni. Magnetic Anisotropy of Ba Ferrite Particles at Low Temperature. Journal de Physique IV Proceedings, 1997, 07 (C1), pp.C1-739-C1-740. 10.1051/jp4:19971301 . jpa-00255068

\section{HAL Id: jpa-00255068 https://hal.science/jpa-00255068}

Submitted on 1 Jan 1997

HAL is a multi-disciplinary open access archive for the deposit and dissemination of scientific research documents, whether they are published or not. The documents may come from teaching and research institutions in France or abroad, or from public or private research centers.
L'archive ouverte pluridisciplinaire HAL, est destinée au dépôt et à la diffusion de documents scientifiques de niveau recherche, publiés ou non, émanant des établissements d'enseignement et de recherche français ou étrangers, des laboratoires publics ou privés. 


\title{
Magnetic Anisotropy of Ba Ferrite Particles at Low Temperature
}

\author{
G. Bottoni \\ INFM, Dipartimento di Fisica, Università, 44100 Ferrara, Italy
}

\begin{abstract}
The evolution of the magnetic anisotropy of pure and Co/Ti-doped $\mathrm{Ba}$ ferrite particles from room to low temperatures is studied analyzing the variation of the anisotropy constants with $T$. These constants increase with the decrease of temperature in different ways in the two types of particles. In pure particles the magnetocrystalline anisotropy constant $\mathrm{K}_{1}$ is larger than the conflicting shape anisotropy constant $\mathrm{K}_{\mathrm{s}}$ at low as at room temperature, which means uniaxial anisotropy, in all the analysed range of temperatures. In the doped particles, where the substitutions weaken the crystalline anisotropy, at low temperature $\mathrm{K}_{\mathrm{s}}>\mathrm{K}_{1}$, then the particle is not any more uniaxial, but the easy axes have multiple directions.
\end{abstract}

\section{INTRODUCTION}

In Ba ferrite particles, as it is known, both magnetocrystalline and shape anisotropies, with different easy magnetization directions, are present. The crystalline anisotropy is uniaxial, with easy direction in the $c$ axis perpendicular to the hexagonal plane of the platelet-like particle. The dependence of the anisotropy energy density on the angle $\theta$ between the magnetization and the $\mathrm{c}$ axis is:

$$
\mathrm{E}_{\mathrm{k}}=\mathrm{K}_{1} \sin ^{2} \theta+\mathrm{K}_{2} \sin ^{4} \theta
$$

The shape anisotropy has an easy magnetization plane in the platelet plane, at right angles to the magnetocrystalline anisotropy axis. The two anisotropies are conflicting: the easy axis of crystalline anisotropy is a difficult axis for shape anisotropy and viceversa. The energy density of the shape anisotropy in the direction defined by the angle $\theta$ with respect to the $c$ axis is:

$$
\mathrm{E}_{\mathrm{s}}=\mathrm{K}_{\mathrm{s}} \sin ^{2}(\pi / 2-\theta)=\mathrm{K}_{\mathrm{s}} \cos ^{2} \theta
$$

where $\mathrm{K}_{\mathrm{S}}=1 / 2 \mathrm{NM}^{2}$ with $\mathrm{N}$ the difference between the demagnetizing factors in hard (c axis) and easy (platelet plane) directions. The total anisotropy energy density is:

$$
E=E_{k}+E_{s}=\left(K_{1}-K_{s}\right) \sin ^{2} \theta+K_{2} \sin ^{4} \theta+\text { const }
$$

Both anisotropies are temperature-dependent, the shape anisotropy through its relation with the saturation magnetization. We have analysed the evolution of magnetic anisotropy of Ba ferrite particles when cooled from room to low temperatures, studying both pure and $\mathrm{Co} / \mathrm{Ti}-$ doped particles for magnetic recording media.

\section{RESULTS AND DISCUSSION}

The magnetocrystalline anisotropy increases when the temperature decreases. In pure Ba ferrite, the first order anisotropy constant $K_{1}$ passes from $3.3 \cdot 10^{6} \mathrm{erg} / \mathrm{cm}^{3}$ at room temperature to $4.3 \cdot 10^{6} \mathrm{erg} / \mathrm{cm}^{3}$ at $\mathrm{T}=90 \mathrm{~K}$ [1]. The variation of the shape anisotropy constant with the temperature arises from the variation of the magnetization with $\mathrm{T}$. We have measured the dependence of $M$ on temperature in particles of pure $B a$ ferrite with aspect ratio $d / h \sim 3: 1$ and static coercivity $H_{c}=2800$ Oe at room temperature. $M_{S}$ results to change from $375 \mathrm{emu} / \mathrm{cm}^{3}$ (room temperature) to $520 \mathrm{emu} / \mathrm{cm}^{3}(\mathrm{~T}=90 \mathrm{~K}$ ) [2] . Then, being $\mathrm{N}=8.16$ for the above mentioned aspect ratio, $\mathrm{K}_{\mathrm{s}}$ is $5.7 \cdot 10^{5} \mathrm{erg} / \mathrm{cm}^{3}$ at room temperature and $1.1 \cdot 10^{6}$ $\mathrm{erg} / \mathrm{cm}^{3}$ at $90 \mathrm{k}$. Both at room and at low temperature the constant of crystalline anisotropy $\mathrm{K}_{1}$ is larger than the constant of shape anisotropy $\mathrm{K}_{\mathrm{S}}$ in the particles of pure $\mathrm{Ba}$ ferrite. This means that in all the analysed range of temperatures the magnetic anisotropy is substantially uniaxial, with easy axis perpendicular to the hexagonal plane. 


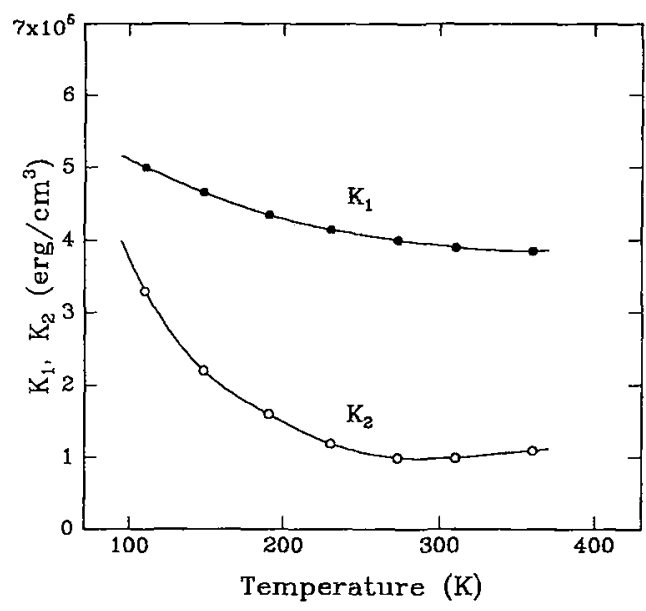

Fig. 1. Temperature dependence of magnetocrystalline anisotropy constants $K_{1}$ and $K_{2}$ of Co/Ti-doped Ba ferrite particles [3].

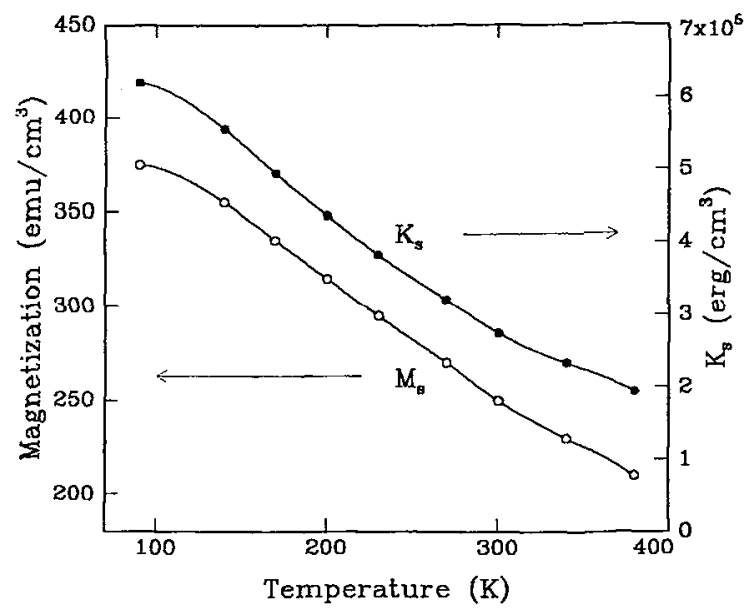

Fig. 2. Temperature dependence of saturation magnetization $M_{S}$ and shape anisotropy constant $\mathrm{K}_{\mathrm{s}}$ of $\mathrm{Co} / \mathrm{Ti}$-doped $\mathrm{Ba}$ ferrite particles.

In $\mathrm{Ba}$ ferrite particles modified with the addition of $\mathrm{Co} / \mathrm{Ti}$ ions for the use in recording media $\mathrm{BaFe}_{10.3} \mathrm{Co}_{0.85} \mathrm{Ti}_{0.85} \mathrm{O}_{19}$, the magnetocrystalline anisotropy is remarkably lowered by the ionic additions. The variation of the constants $\mathrm{K}_{1}$ and $\mathrm{K}_{2}$ with the temperature, as reported by $O$. Kubo and E. Ogawa, is shown in Figure 1 [3]. We see that $\mathrm{K}_{1}$ changes from $\sim 4 \cdot 10^{5}$ $\mathrm{erg} / \mathrm{cm}^{3}$ at room temperature to $\sim 5 \cdot 10^{5} \mathrm{erg} / \mathrm{cm}^{3}$ at $90 \mathrm{~K}$, whilst $\mathrm{K}_{2}$ passes from $1 \cdot 10^{5}$ (room temperature) to $3.5 \cdot 10^{5} \mathrm{erg} / \mathrm{cm}^{3}$ at $90 \mathrm{~K}$. In particles with such doping content, the measured magnetization increases when $T$ decreases as reported in Figure 2, and particularly it passes from $250 \mathrm{emu} / \mathrm{cm}^{3}$ at room temperature to $375 \mathrm{emu} / \mathrm{cm}^{3}$ at $90 \mathrm{~K}$. Considering the aspect ratio $\mathrm{d} / \mathrm{h} \sim 4: 1$ of the particles we have evaluated and the consequent demagnetizing factor $\mathrm{N}=8.8$, the shape anisotropy constant $\mathrm{K}_{\mathrm{S}}$ varies with the temperature as shown in Figure 2. Particularly, $\mathrm{K}_{\mathrm{S}}$ is $2.75 \cdot 10^{5} \mathrm{erg} / \mathrm{cm}^{3}$ at room temperature and $6.2 \cdot 10^{5}$ $\mathrm{erg} / \mathrm{cm}^{3}$ at $90 \mathrm{~K}$.

This evolution of the anisotropy constants gives rise to a change of the magnetic anisotropy status of Co/Ti-doped particles with the temperature.

At room temperature $\mathrm{K}_{1}-\mathrm{K}_{\mathrm{s}}$ is positive and the magnetic anisotropy is practically uniaxial, with $c$ easy axis. At low temperature the situation is different. At $90 \mathrm{~K}$, for instance, $K_{s}$ is larger than $K_{1}$, then $K_{1}-K_{s}$ is negative, and its value is $-1.2 \cdot 10^{5} \mathrm{erg} / \mathrm{cm}^{3}$. In such conditions, the magnetic anisotropy is not uniaxial. From eq. (3) the magnetization results to have a stable equilibrium at:

$$
\theta_{0}=\sin ^{-1}\left[-\left(\mathrm{K}_{1}-\mathrm{K}_{\mathrm{s}}\right) / 2 \mathrm{~K}_{2}\right]^{-1 / 2}
$$

With the obtained values for the anisotropy constants at $90 \mathrm{~K}$, it results that $\theta_{\mathfrak{O}}=24.5^{\circ}$. Then the easy magnetization axes are distributed on a cone surface with the $c$ axis as the axis of the cone and top angle amplitude $\theta_{0} . K_{s}$ becomes larger than $\mathrm{K}_{1}$ at a temperature near $200 \mathrm{~K}$, as it appears comparing Figures 1 and 2. Above such critical temperature the anisotropy is uniaxial, below it gives rise to a preferred cone for the magnetization. This deviation from the perpendicular anisotropy is due to the single ion contribution to the magnetocrystalline anisotropy given from the added $C_{0}$ ions. The angle $\theta_{\circ}$ depends on the value of the constants of anisotropy, then of the content of Co and Ti ions. A further increase of the doping ion content would increase $\theta_{0}$ and the critical temperature.

Then the magnetic anisotropy feature of $\mathrm{Co}$ /Ti-doped $\mathrm{Ba}$ ferrite particles for magnetic recording is remarkably different at low with respect to room temperature, with appearance of multiple anisotropy axes. This will have noticeable effects on the magnetic behaviour of the material, for example on the thermal stability of the magnetic properties, which should show an anomalous weakening with the decrease of temperature [4].

\section{References}

[1] Smit J. and Wijn H.P.J., Ferrites (Philips Tech. Lib., Eindhoven, 1959) p. 205.

[2] Corradi A.R., Speliotis D.E., Bottoni G., Candolfo D., Cecchetti A. and Masoli F., IEEE Trans. Magn. 25 (1989) 4066-4068.

[3] Kubo O. and Ogawa E., IEEE Trans. Magn. 27 (1991) 4657-4659.

[4] Bottoni G., Candolfo $\mathrm{D}$. and Cecchetti A., "Time-dependent magnetic behaviour of Ba ferrite particles at low temperature" Intermag '96 Conference, Seattle, April 1996. 